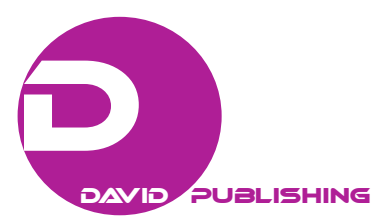

\title{
Engineering of Convergence and Divergence and Its Modeling in the Production of Knowledge
}

\author{
Manuel Vicente Castillo Guilarte \\ National Experimental Polytechnic University (UNEXPO), Caracas, Venezuela
}

\begin{abstract}
Once started the Doctorate of Management Research and Development (DGID) at the Central University of Venezuela, and having been approved by the National Council of Universities since 2008, at the Seminar on Management of Science and Technology at two courses in year 2015, it was possible to form a population of analysis with 88 participants; during the first two class sessions of each course, each trainee was required curricular synthesis and the issue/summary of the research work, along with a short exposure, and simultaneously with the application of an open survey had as a general question: Do you know how to generate or produce new knowledge? Getting increasingly negative response, which partially explains the reasons why in Venezuela the performance of graduates at doctoral level reaches an average of $10 \%$ of tuition income, situation known as the phenomenon of all but dissertation (Gascón, 2008). Taking it as a case study in which the DGID enrollment in seven years was 120 trainees, who in five years were required to obtain the maximum degree, the national problem in which the same scenario is repeated evidence (Castillo, 2014), since 2015, there will have only 11 graduates. From a descriptive methodology, case study from a survey with a deductive and inductive analysis, aiming to research the use of the theory of Engineering Convergence and Divergence, to define and propose a new model to establish guidance patterns for the production of knowledge, is obtained as a result of the investigation, the defined model will establish order, sequence, and systematization of the problem, theories, and solutions in time, so to collaborate with an increase in knowledge production, hoping to contribute to the partial solution to the problem of national character.
\end{abstract}

Keywords: convergence engineering, generation of knowledge, syndrome quite less thesis

\section{Introduction}

In Venezuela, the problem of knowledge production is in steady decline, so that today ranks last in patents and publications in South America and was recorded in the newspaper Venezuelan Circulation the World the November 11, 2013, this news being an alarm; therefore, it is necessary to generate new patterns, theories, concepts, and models to assist in obtaining a solution or guide to give a leap that should investigate and generate knowledge; in this sense, they have taken the concepts of convergence and divergence under an engineering approach to define a model that following a particular procedure, which can be produced with certainty needed to regain the levels of productivity in the country knowledge, helping student to complete their

Manuel Vicente Castillo Guilarte, Ph.D., full professor, Department of System Engineering, National Experimental Polytechnic University (UNEXPO), Caracas, Venezuela.

Correspondence concerning this article should be addressed to Manuel Vicente Castillo Guilarte, Department of System Engineering, campus Vice-Rectorado "Luis Caballero Mejías”, UNEXPO, Km.0, Av. Principal, Urb. La Yaguara, Mun. Libertador, Caracas CP 1000, Venezuela. 
schooling and their work degree and doctoral thesis, including those that investigate and innovate. It is convenient to emphasize that exists in Venezuela legislation related to the subject, and in this respect the General Regulations of Graduate Studies 2001 in its Article No. 26 states: "doctoral studies are aimed at training to perform work original research that constitutes a significant contribution to the body of knowledge of a specific area of knowledge”. So that, the doctorate is to build a significant original contribution in science, compelling the production of knowledge (Morin, 2004); only the doctoral thesis at the graduate level is developed with the aim of generating new knowledge (Humberto, 2011). There is a non-binding approach that is defined in the Universities Act of 1970 in its Article No. 89, which states that teaching staff and research to climb the ladder must submit an original work for consideration by a jury appointed for the effect, which was ratified in echelon Standards of Teachers and Research of National Universities 1995, which states in Article No. 5 that the promotion work must be original and innovative; but it is clear that there being the use and arrangement of theories, models, analysis, and application of knowledge in general, only a small percentage succeed give more than required. It follows from that level only doctoral thesis is clear the requirement of knowledge production; all products that can be obtained in research projects, innovations, promotion work, and doctoral theses, which ultimately is reflected in patents, which acts as a meter and catalyst activity in the area.

There are a variety of problems related to low knowledge production in Venezuela, being the highlights.

The percentage of students who graduated with doctorates as a source of knowledge production in Venezuela is about $10 \%$ of tuition income, which defines low efficiency in this school. This ranges on average from $0 \%$ to $15 \%$ annually, there being a single peak value of $90 \%$ at a university in the country, which are reflected by the universities themselves or by the National Advisory Council of Graduate Venezuela (www.ccnpg.gov.ve), and the most important causes of this phenomenon are: lack of motivation, safety, suitable guardians, and time and sequence (Rodríguez, 2013). According to information from the historical pattern of patent in Venezuela and Venezuelans in the US, a drop of $98 \%$ is reflected, placing the country in the last countries in Latin America, which has been part of the policy of the national executive to promote the discrediting of patents over the last 10 years and the actors who are required to produce knowledge such as university professors, are not complying with it since by law they are obliged to investigate and additionally to move up the ladder in the category of associate professor and head, they require title of doctor but persist in most of the country's universities for an exceptionality not meet the requirement of a doctoral degree (Castillo, 2010). Therefore, experts for excellence in generating patents are university professors but if they do not fulfill their obligations, they would not have the right experience to support others, which becomes a vicious circle. Although, all student doctorates are required by the program to attend the research methodology course and in some cases the research workshop with their respective tutor, there are no models or patterns adapted to reality in Venezuela to support the generation of knowledge; it is the guardians, who should have a high level of expertise in the field of doctoral thesis, publication, incubation, prototypes and patents, and in some cases part of the problem (Rodriguez, 2013). With this variety of drawbacks, then the objective of the work is defined: Defining a production model and/or generation of knowledge-based engineering convergence and divergence, systematizing, sort, and organize sequentially doctoral students, to increase knowledge production in Venezuela.

The paper is organized as follows: in section 2, the theoretical framework is defined based on convergence, divergence, convergent and divergent thinking, engineering convergence and divergence, as well as some history of models that could adjoin research; in section 3, methodology and data collection tools such as a 
survey supported the case study is established; in section 4, the proposal of a model of knowledge production is presented; section 5 raises the interpretation of the model and finally the conclusions are made.

\section{Support Theory to the Investigation}

The main theoretical foundations that allowed the development of this research are divided into four sub-sections in the following order: first, Convergence and Divergence (C\&D); second, thinking convergent and divergent; third, engineering convergence and divergence; and finally, the background of knowledge production models.

\section{Convergence and Difference}

The concept begins to understand its meaning from the dictionary, in which it has: Convergence is a word that comes from the Latin "convergens" which "with" is meeting and "vergens" tilt. The most general meaning of convergence is the union of two or more things that flow or seek the same point, and divergence is a Latin word "divergens" divergent. It is interpreted as diverging action and effect of progressive separation of two or more lines or surfaces, disagreements diversity, diversity of opinions. In a global view, both concepts are opposite to each other, and their application touches all disciplines of knowledge which would be defined as a term of the theory of transdisciplinarity, with a vision of learning (Aparicio, 2010) and are also terms that should be part of the integral formation of the individual in their cognitive and comprehensive training and establishing curriculum changes from the perspective of convergence and divergence (Sanmamed, 2013). These abstract terms have been studied by many authors, and yet the question is: how the human mind and how it relates to the convergence and divergence works?. That's why then the convergent and divergent thinking (Kim \& Pierce, 2013) is defined.

\section{Convergent and Divergent Thought}

Throughout history, there are many treaties, but Guilford in 1957 established the classification of productive thinking into two groups: divergent and convergent. Convergent thinking, also called logical, conventional, or vertical, is looking for a unique answer as correct solution to the problems, the solution may be known; De Bono (1970) related logical thinking and deductive hypothetical, and in 1986, they gird it argued as the hypothetical deductive method based on constructing hypotheses and in the field of experimentation, which predictes or confirms a theory, laws, models, or mathematical formulas, resulting in important vertical logic rationality.

Divergent thinking is pointed out by the authors as a generator of different solutions to a problem in different directions, looking for the best; facing the new and prone to creativity and ingenuity, has also called lateral thinking by De Bono in 1970, as well as holistic thinking defined by Jan Smuts in 1927, in which the analysis is the whole and not parts, including as term "see the forest and not the tree". There is a mechanism associated with creativity, which is the retrospective perception and intuition; according to history, they established that the great discoveries have been produced by schema changes through casual observations, accidents, mistakes, and mood (Vidler, 1974). Del Río Pérez (2007) characterized the creative thinking of an individual and related to intellectual structure of the subject, its characteristics and mental abilities but, Guilford (1957) raised that creative people are those who must have convergent thinking, divergent thinking, and theory of the structure of intellect. At first, human development focused on intelligence, knowledge, memory, logical thinking or convergent, and then divergent production joined (Hurtado, 2008). Knowledge production, in the first instance, is closely linked to the interaction of vertical and lateral thinking, where, lateral thinking is who 
increases the efficiency of vertical thinking (De Bono, 1970). When defining a variety of new ideas, selecting the most appropriate, it is lateral thinking who can create new ideas and approaches to solving problems and situations or describe new problems and their selection and final argument for the vertical thinking of variables such as intelligence, level of knowledge, experience, safety, depth in learning, systemic, skills, language, logic, humor, insight, motivation, and emotions (among other variables). All these are what make the difference, to raise and maintain a high percentage of constant creativity or when required (Berkowitz, 2014).

\section{Engineering of Convergence and Divergence}

The basis of engineering is creativity, which is to change or transform an existing field in a new one allowing innovation (Boccarda, 2006).

The significance of this section is to emphasize that the training in engineering involves implicit in all its learning convergence and divergence that must design, modify, transform, and create, and the interesting thing is that there is no subject or seminar in curriculum plan studying how to be creative, innovative, convergent, and/or divergent, it is performed implicitly.

The word engineering comes from engineer, originally from the Latin "ingenium”, wit, therefore, engineering is generally defined as study and application of science and technology to solve problems and meet human needs using ingenuity and ingenuity, based on techniques, models, methods, design, development, production, construction, operation, and maintenance of all physical and natural structures of human reality. Engineering education is a part of a curriculum involved in income during the race and egress from it. For admission, the selection which makes the vast majority of universities is based on choosing people with high ability of logical thinking and spatial reasoning and then priority variables, their training throughout the year follows a sequential process and continues to maintain among many other elements, the discipline of convergence and divergence, and finally, after graduating with a number of professional skills they will have creativity, analytical ability, convergent and divergent thoughts, designer, serendipity, and interdisciplinary (González, 2008).

The curriculum of the engineering career starts with mathematics, physics, and chemistry, and from mathematics, teaching-learning chain elements that are always divergent to set knowledge organized, an example is representing the different levels of calculations and mathematical analysis, in which there are lines of learning as numbers, variables, polynomials, functions, series, and transforms (Ziman, 1986); and in each, limits apply, derivatives, integrals, approximations in one, two, or three dimensions. When speaking of a mathematical division of one third $1 / 3$, really value is 0.3333 which ends at infinity but does not understand this process is necessary to go to the philosophy of mathematics, however, if maintained the continuity of the division, it will be writing both the decimal, which would leave the earth and through space, to infinity, that is, not end, which allows you to project the mind into a divergent process that when done the approach to two decimal places, it is convergent (Cropley, 2006).

When analyzing hydraulic engineering in their academic program distribution networks, white water, it is designed based on divergence, when he treated the wastewater collection network as a convergent process to the treatment plant.

In the case of terrestrial telephone networks, centered nodes, the design is based on how users connect from their phones to a node, and this in turn are chains of nodes, until the other user; from the user is convergent and divergent; from the node, with the characteristic that must be bidirectional. And distribution networks of electricity, design of cities, urbanization, infrastructure, and gas. In the area of chemical from the 
subject to the atomic levels, but convergence is applied, the output level of divergence atom applies. All these elements are gradually forming the convergent and divergent thinking, as a necessity consciously or not, remain a vital element in professional practice in reality (Martínez, 2002).

They based the theory that engineering is based on the application of convergence and divergence in the next section will come up with some background and generation models based on engineering knowledge convergence and divergence.

\section{Precedents of Models of Production of Knowledge Based on the Engineering of Convergence and Divergence}

In conducting documentary research, one of the premises of previous models is that multiple intelligences (Gardener, 1995) posed starting from the human genetic heritage, training, education, knowledge, and skills make every individual has a vocation, and then the model of rational and emotional intelligence establishes intellectual abilities (Goleman, 1996).

By increasing the accuracy of searching for models of knowledge production based on C\&D models they were found linked indirectly:

- A model of the productivity GAP: Convergence or Divergence? (Harris, 2013) Which links productivity and its solution through convergence and divergence analysis to solve problems?

- Convergence and divergence simultaneous modeling of linguistic, the relationship between different groups aroses to determine their traits from the convergence (Wedel, 2008).

- Enterprise resource planning and organizational knowledge: Patterns of convergence and divergence (Baskerville, Pawlowski, \& McLean, 2000), are the study and analysis of how to plan and organize resources and knowledge of the company with patterns of convergence and divergence.

Search with previous models was determined, which is not similar to the research of this paper, therefore, it cannot be said to exist and check previous models reinforcing the importance of this research.

So far, the theoretical support and support for the work is completed, then the methodology that allowed its development arises.

\section{Research Methodology}

The research is based on a case study from a survey and analysis of the information developed in other areas of knowledge and its application in the field to relate the dynamics of the problem in time and knowledge generation. Applying a descriptive methodology, deductive analysis and taking into account different sciences, this research begins by locating and studying the sources of information and how to analyze and interpret critically and independently ideas related to the subject, and then refers them as variables involved in a basic model of knowledge generation. For the definition of the problem and its justification, a survey was conducted to a population consisting of doctoral trainees, who are starting or pursuing two semesters of no more than doctoral program; it is characterized curricular who participated and the generation of knowledge and innovation they had experienced in their respective professions analyzed. The next section is a continuation of two pates, curriculum characterization of each trainee and implementation of the survey.

\section{Survey of Population Study}

For this research, a survey in the Central University of Venezuela at the Faculty of Economics and Social Sciences, Graduate Studies Committee, specifically in the doctorate of research and development management, 
is characterized by being face-time and developed; its application was immersed in the corresponding academic activities management seminar science, technology and innovation, which is mandatory, groups of trainees in each half come from 2008 to 2015, i.e., it was possible to application 14 times, accumulating a total of 88 professionals doctoral students.

At the beginning of each six-month period, they were asked individuals from each group:

- Synthesis curricular.

- Theme and written summary of his research.

- Presentation in 10 minutes summary of the research work.

- A 15-minute presentation in mid-semester professional experience own innovation, invention, patent, or knowledge generation.

The first, consisting of the tantalization of curricular synthesis; and the second, application of open survey for eight consecutive years: the above procedure, two data structures were obtained.

Analysis of the curricular synthesis of the 88 trainees attending the seminar management in science and technology doctorates, related variables graduate and income profile, of which the percentages were obtained in related to the totality to determine differences that were considered and patterns and how that support them, ensure continuity, and complete his doctoral studies. This information is reflected in Table 1.

Table 1

Information Curricular of the Students of the Doctorate GID.

\begin{tabular}{ll}
\hline Variable analysis & Accumulated results \% \\
\hline It has a postgraduate degree or master's level of expertise & 64 \\
It has more than one title of graduate-level specialization or expertise & 19 \\
It holds a doctoral degree & 1 \\
Doctoral seminars have other postgraduates & 6 \\
It has unfinished doctoral studies thesis & 4 \\
He is a university professor & 26 \\
Professor hired some college & 17 \\
Administrative staff is college & 9 \\
A teacher or student from another country & 3 \\
Other graduate studies in parallel to the doctorate & 7 \\
He has completed research methodology & 87 \\
It is nationally accredited researcher & 27 \\
Aged between 30 and 50 years & 91 \\
This exclusive dedication in the PhD & 9 \\
\hline
\end{tabular}

The curriculum synthesis information was supplied by email as a reference to research each student intended to make.

Because as mentioned above, this doctorate is attending classes, the survey was conducted in the classroom during the second class session, each trainee without form; the total respondents were 88 trainees of the seminar with the curricular diversity posed above.

The survey questions were:

(1) Have you produced a new global knowledge?

(2) Do you know how to produce new knowledge?

(3) Do you know the techniques or models that will guarantee to produce new knowledge? 
(4) Would you like to know models that support and organize the production of knowledge?

(5) Would you like to build and develop new theories?

(6) Are you ready to produce new knowledge?

Once the survey conducted, the results presented in Table 2 were obtained. These results expressed in percentage terms state that there are difficulties, ignorance, and concern to develop the doctoral thesis in which they must produce new knowledge.

Table 2

Results of the Survey Valued in Percentage.

\begin{tabular}{lll}
\hline Question & Yes & No \\
\hline I & $1 \%$ & $99 \%$ \\
II & $2 \%$ & $98 \%$ \\
III & $31 \%$ & $69 \%$ \\
IV & $99 \%$ & $1 \%$ \\
V & $86 \%$ & $14 \%$ \\
VI & $0 \%$ & $100 \%$ \\
\hline
\end{tabular}

Analysis of the curricular synthesis of doctoral trainees is in a definite pattern, since it is not homogeneous and therefore inconclusive; however, if there were 11 graduates of doctor in eight years, the project in five years, is to ensure that all completed by simple relationship would have 18 graduates; analyzing the curricular information, there are three variables weight; the first $64 \%$ of the trainees have graduate, which makes them be prepared as a researcher; $43 \%$ are teachers, which implies they are bound to be an associate professor or holder have the title of doctor, and there being $27 \%$ of researchers nationally accredited students have publications in magazines and attending academic conferences; there is another variable in small amounts, in which $9 \%$ of students are dedicated to the doctoral program; to perform the arithmetic average among those who are dedicated and are accredited researchers, the result is $18 \%$, which represents 16 graduates close to projections.

The study of curricular synthesis focuses the problem in dedication to study, and it is the most associated variable to the national problem that only $10 \%$ of income, graduate, if the demands low climb enrollment proportionally, but in term of keeping doctorates in operation, must seek complementary solutions.

The most important survey is that students feel they are not prepared to generate new knowledge, but they know they must acquire the necessary skills during schooling doctorate for the thesis and a high percentage would like to meet new models that support the production of new knowledge, students are aware of the percentage of graduates is $10 \%$, the time of the survey are all safe to conclude.

Then a proposed model appears to produce knowledge, using as a basis the engineering of convergence and divergence.

\section{Proposal: Engineering of Convergence and Divergence and Its Modeling in the Production Knowledge}

The model is presented in four stages: dynamic problem, management, temporary, and final.

All researches start with a problem or event, necessarily, the problem must be valid and belong to this but it turns out that time is a variable continuous increase and does not stop, which states that what is now present, becomes past, this implies that the problem is a transition among future, present, and past, and depending on your solution will be only in the past. To demonstrate this dynamic, set in Figure 1, there is a problem in this $P 1$ comes from the past and future will continue until a solution is known. 


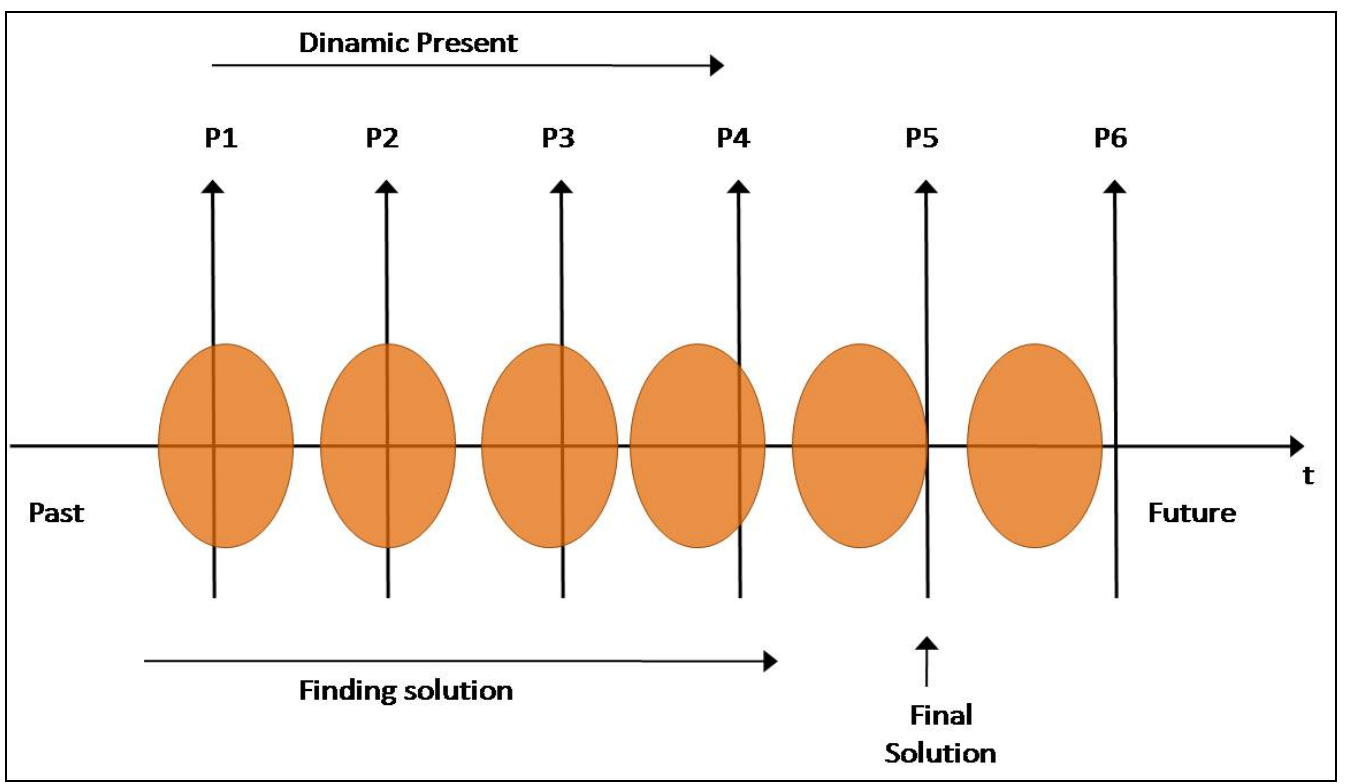

Figure 1. Dynamics of a problem in the time.

To the extent that the time is changing and the solution is developed, the problem is slowly ceasing to exist in the future until it is located in the past once solved, understanding the dynamics over time of a problem allows you to set the goal to stop being a problem and it must be in the past.

The requirement of patent generation becomes an example of the dynamics of the problem, as currently required to generate patents but they come from the production of knowledge, which is embodied in the different doctoral research place in the country, after analyzing engineering convergence and divergence, they could generate a contribution, with a model that helps to organize and outline the problem, theories, solutions, and knowledge production.

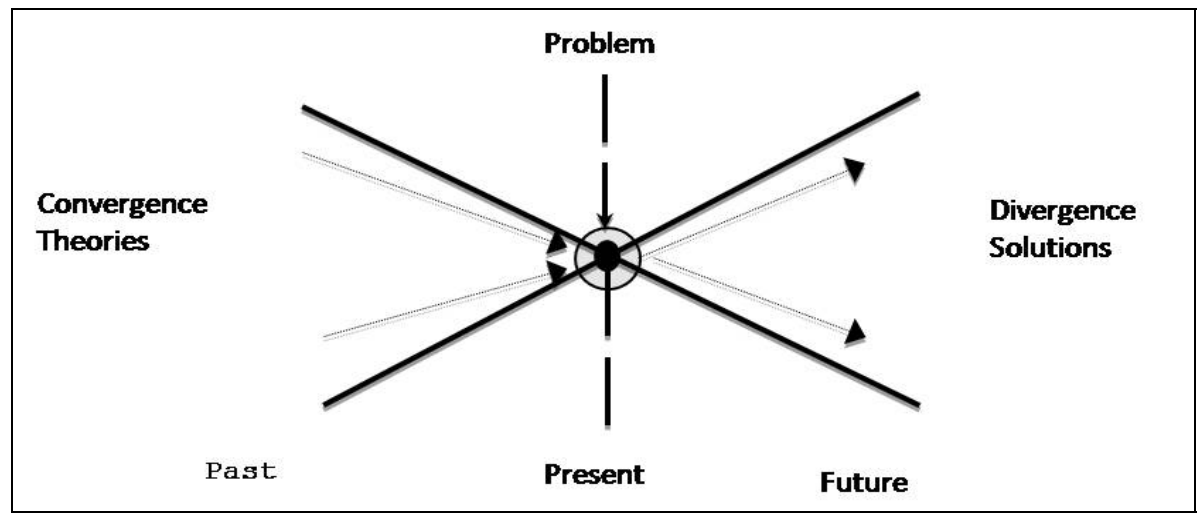

Figure 2. Model general of convergence and divergence in the time.

Figure 2 presents a general model of convergence and divergence occurs in time, in which the past is moved to the present with convergence, allowing stringing the different theories, concepts and leading push to the present, for determine what supports today and into the future. The different solutions that can be given to a hypothesis or a problem would be divergent.

In engineering, it is a network in which they move or move elements, in some cases, it is the fixed part and dynamics, such as electricity, water pipes, pipelines, cables, and phones that work as means of transport 
carrying energy, water, gas, or information signal, that is, there is a means of transport and the element uses the medium. In the case of Figure 2, that the lines are different media and processed information acquired as knowledge, is the element.

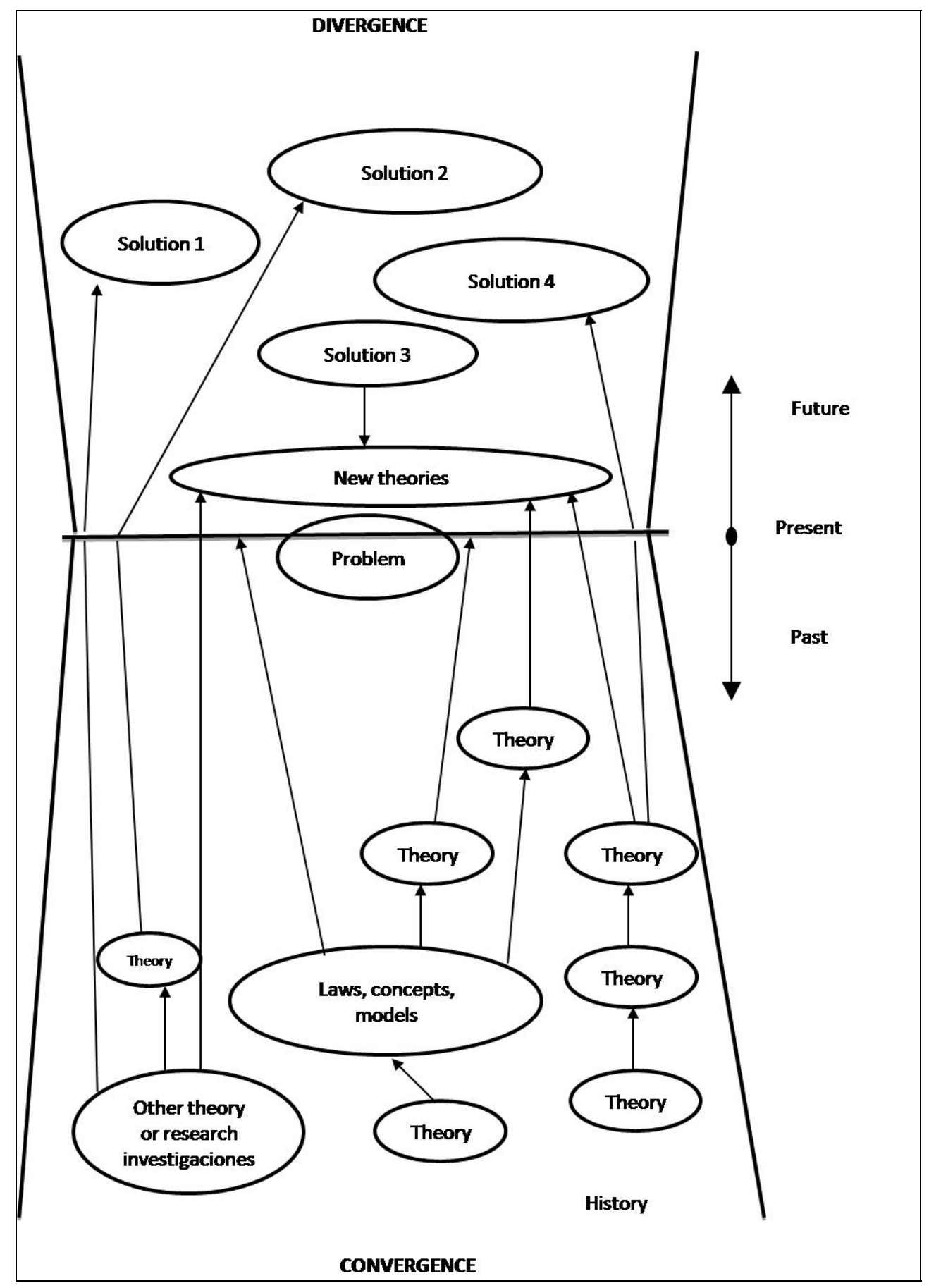

Figure 3 .Temporary model of generation of knowledge based on engineering of convergence and divergence.

Figure 3 presents a temporary model or interface for knowledge management, which sets out how the chains and gears theory move in a convergent manner, based on a problem that requires to define a new theory 
arises from past to present, strengthening the new theory will require to find more theories in the past or validation and verification, being thus begins the two-way.

Similarly, the problem may have infinite solutions but only one of them is applicable and allows the production of new knowledge, this generates a divergent process to solutions with a convergence towards the problem, making bidirectional.

This model is temporary, initially corresponds to one or two theories that support a problem and based on them, a slightly viable solution arises and only through research, the convergence of a theory supported in its history made solutions temporal dynamics does, and grew to conclude in the product.

Figure 4 represents the final model, in which the construct or new theory and knowledge generation and existing theorems and spiky that support materializes; maintaining the timeline and following these three steps, that interest in producing knowledge can maintain a continuous sequence systemic supportimg their goal is the production of knowledge.

For the completion of a research paper or a doctoral thesis participants located throughout its development as defined in Figure 4, so that in sequence it will be: theories that are history, theories that are not required, theory they are joined sequentially as part of the current theory, establishment of the theory of boundary, which are all those who served to support and deduct the new construct, problem seen in the past or being resolved, all raised possible solutions and the new proposal is supported by theory of deductive and inductive methods.

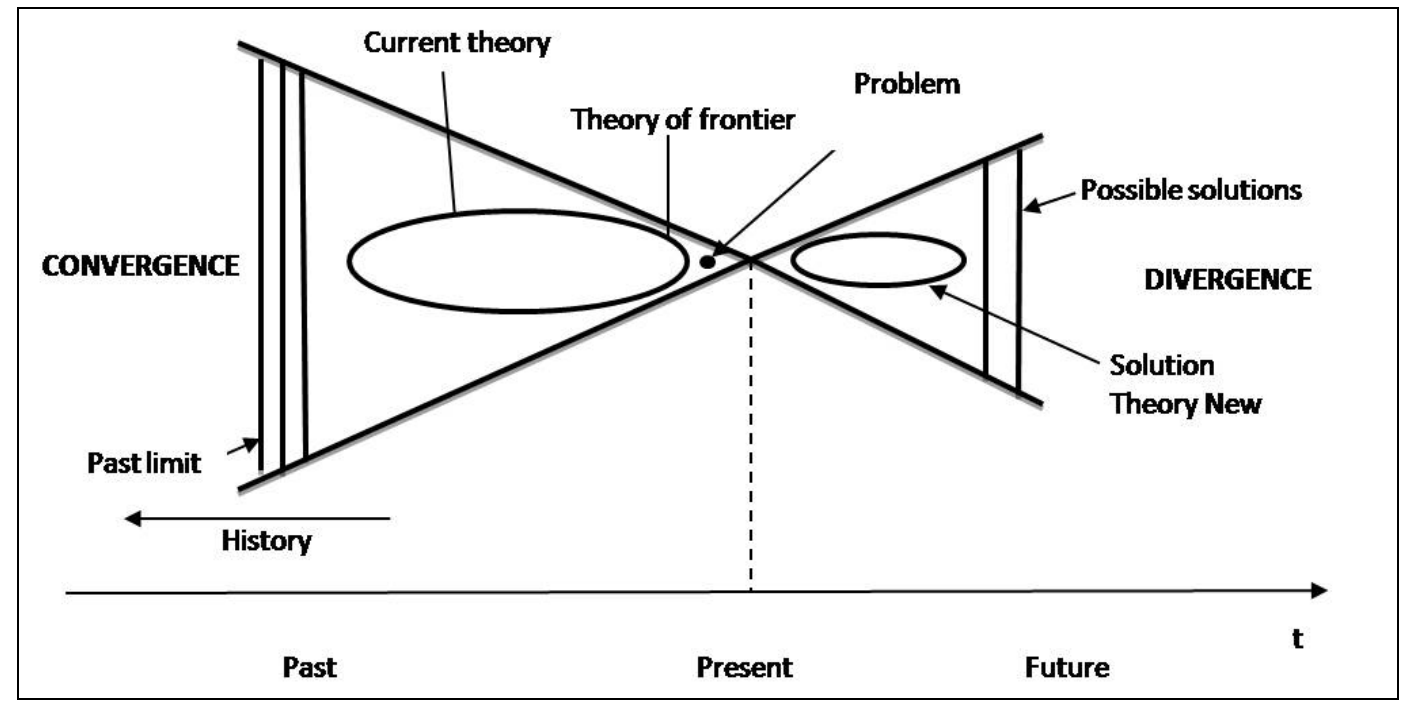

Figure 4. Final model of convergence and divergence.

Interpretation of the Presented Model

The purpose of the model is to support the production of knowledge, by virtue of the problems presented in Venezuela doctorate level, only 10\% finish the doctoral thesis, which for others is required by national law.

A doctoral research cadet must define the problem and the title will be the basis of the solution to the problem's starts. This research was made in four stages model and the question is how this model helps in the field of knowledge.

The four stages of the model are steps in sequential order to maintain a systemic doctoral research, and the steps are: 
The dynamics of the problem set out a secondary objective in the researcher's mind that how to get the problem at present produced in the past and presented in the future continuously, and getting over the investigation problem under study remains only in the past ceased to come to this affecting the future.

The general model of convergence and divergence in time, first the investigator you set should review, study, and analyze the various theories only in order to make a convergence and achieve set divergently infinite solutions.

The display of stringing convergence and divergence with a common point is the problem, taking into account the time, which allows doctors to researchers initially oriented on what to do simultaneously in convergence and divergence in such a way that the more theory, the more possible scientific solutions.

The third stage is where the doctoral researcher will be longer. At this stage, there are several phases: the first is to establish all possible solutions under inductive approach widening divergence, and all theories that may be involved in the second phase should link theory with solutions and determine which theory supports to each solution, what history, what background, and what theories tip.

The third phase should select the solution and establish the elements of each theory that gives partial solution and then deduct the new theory.

In the final model, the doctoral researcher must define and locate all the elements of his thesis, for which places the problem as past, unlike the current theories of the theory of boundary then selecting the solution set the new theory that allows he to generate new knowledge.

\section{Conclusion}

The development of this research is carried out in a proposed model of knowledge generation, for which the engineering process $C \& D$ is applied, making a prototype that doctoral students can use it to systematize his doctoral work and maintain a progressive continuity to achieve the goal.

The proposal is an integrated view of research methodology in which the deductive and inductive method is separately. By keeping the concept C\&D linked by the problem, it occurs more control of the doctoral activity.

The model itself presented in four phases is obtained as a result of a problem and is a new knowledge and its own conception is guided by the same model.

The model proposed production of knowledge is a pattern that can be redefined sequentially as steps for production of knowledge in this way, and it is used as a cognitive tool for doctoral students to continue and stay steady progress in developing its doctoral thesis.

In the temporal model, there are much information between the convergent and divergent, which can be developed in five additional steps to increase the explanation of the model step by step and give a total of eight steps; however this temporary model groups all the information but its use will be alternating convergence and divergence at various points in time of the application.

Taking into account all theory explained when treat research methodology as seminar courses, the scientific method is established, but compared to the proposed model, the latter gives a more systemic and comprehensive scope.

The final conclusion states that what presented is a complementary business model—scientific method, which is used to support generating and/or production of new knowledge in the area of graduate. 


\section{References}

Aparicio, M. (2010). The evaluation of the quality of the university system and employment in their articulation: Towards a transdisciplinario systemic paradigm.

Baskerville, R., Pawlowski, S., \& McLean, E. (2000). Enterprise resource planning and organizational knowledge: Patterns of convergence and divergence. In Proceedings of the twenty first international conference on Information systems (pp. 396-406).

Berkowitz, G. (2014). Convergent and divergent thinking. Encyclopedia of Special Education.

Boccardo, R. (2006). Creative in engineering design. USB. Venezuela: Editorial Equinoccio.

Castillo, M. (2010). Prospects of teaching profession in universities and its relationship with the engineering in Venezuela. Eighth LACCEI Latin American and Caribbean Conference for Engineering and Technology. Arequipa Peru. Paper 163.

Castillo, M. (2014). Engineering of convergence and divergence and modeling in the production of knowledge. Presented at the VII International Meeting Management Research and Development (AVEGID) Granada-Cartuja-Spain. Paper 2-1.

Cropley, A. (2006). In praise of convergent thinking. Creativity research journal, 18(3), 391-404.

De Bono, E. (1970). Lateral thinking a text book of creativity. UK: Mica Management.

Del Río Pérez, J. (2007). Review of psychological research on creativity observatory (OBS).

Gardener, H. (1995). The multiple intelligence. Harvard University.

Gascón, Y. (2008). Syndrome all but dissertation, without thesis “TMT” as a factor in/Uential in the research work. Journal Copérnico, 1(9), 57.

Goleman, D. (1996). Emotional intelligence. España: Editorial Kairos.

González, J. (2008). Convergence, divergence and accreditation in engineering education. Journal of Higher Education, 37(147), 89-105.

Guilford, J. P. (1957). Creative abilities in the arts. Psychological Review, 64(2), 110.

Harris, D. (2013). A model of the productivity gap: Convergence or divergence. US: Stanford University.

Humberto, E. (2011). How do you write a thesis. Barcelona: Editorial Gedisa.

Hurtado, J. (2008). Formulating research objectives. Venezuela: Quirón.

Kim, K. H., \& Pierce, R. A. (2013). Convergent versus divergent thinking. In Encyclopedia of Creativity, Invention, Innovation and Entrepreneurship (pp. 245-250). New York: Springer.

Martínez, M. (2002). The emerging paradigm. México: Tillas.

Morin, E. (2004). Introduction to complex thought. Barcelona: Gedisa.

Rodríguez, M. (2013). Everything but thesis syndrome (TMT). A phenomenology in postgraduate studies, graduate research, electronics journal. UNERG, No. 3, pp. 1-6.

Sanmamed, M. G. (2013). Convergence vs. divergence diferences in the desigm of practicum. A Practcum for Integral Training of Students. Coruña University.

Vidler, D. (1974). Convergent and divergent thinking, test-anxiety, and curiosity. The Journal of Experimental Education, 43(2), 79-85.

Wedel, A. (2008). Modeling simultaneous convergence and divergence of linguistic features. Arizona University.

Ziman, J. (1986). Introduction to the study of science. Barcelona: Arial. 